\title{
Editorial
}

\section{Advances in Building Technologies and Construction Materials}

\author{
J. M. P. Q. Delgado, ${ }^{1}$ Robert Cerný, ${ }^{2}$ A. G. Barbosa de Lima, ${ }^{3}$ and A. S. Guimarães ${ }^{1}$ \\ ${ }^{1}$ CONSTRUCT-LFC, Civil Engineering Department, Faculty of Engineering, University of Porto, 4200-465 Porto, Portugal \\ ${ }^{2}$ Department of Materials Engineering and Chemistry, Faculty of Civil Engineering, Czech Technical University in Prague, \\ Thákurova 7, 16629 Prague 6, Czech Republic \\ ${ }^{3}$ Department of Mechanical Engineering, Federal University of Campina Grande, 58429-900 Campina Grande, PB, Brazil
}

Correspondence should be addressed to J. M. P. Q. Delgado; jdelgado@fe.up.pt

Received 4 October 2015; Accepted 4 October 2015

Copyright ( 2015 J. M. P. Q. Delgado et al. This is an open access article distributed under the Creative Commons Attribution License, which permits unrestricted use, distribution, and reproduction in any medium, provided the original work is properly cited.

The development of civil engineering in the course of centuries meant a constant struggle with available materials, spans, or height, active loads, and the forces of nature: water, fire, wind, and earthquakes.

While construction activities improve the quality of human lives, they also have significant impact on the environment. The production of construction materials requires energy and generates greenhouse gases. Low cost or affordable construction technologies and building materials are often pushed as a magic potion in meeting the ever-growing demand for rapid housing delivery in developing economies. New advanced materials offer opportunities to change the way in which we construct and retrofit buildings. They give added value in terms of increased performance and functionality. The reduction of carbon footprint for construction materials can start at the production phase, where energy efficient processes can be developed and waste or recycled materials can be employed. New materials can also help address the new challenges of durability in a changing climate.

This special issue had a great acceptation by the scientific community with 175 papers submitted.

A considerable number of experimental and numerical papers address new research advances and applications in concrete material. D. Saje studies the reduction of the early autogenous shrinkage of high strength concrete; Z. Zhu et al. analyse the influences of iron ore tailings as fine aggregate on the strength of ultra-high performance concrete; D.-S. Seo et al. present a vision-inspection system for residue monitoring of ready-mixed concrete; G. Xing et al. evaluate the performance of existing concrete structures reinforced with plain bars with bond behaviour.

The chemical attack of concrete structures and other building materials is analysed in detail by some authors. $H$. Yang et al. present the effects of sulphate attack and freeze-thaw alternation on the concrete microstructure; W.J. Fan and X.-Y. Wang describe a numerical procedure to analyse simultaneously cement hydration reaction and chloride ion penetration process; $\mathrm{Z}$. Liu et al. study the effects of seawater corrosion and freeze-thaw cycles on the structural behaviour of fatigue damaged reinforced concrete (FDRC) beams; C. Mi et al. analyse of the durability of sealable circular concrete structures under chloride environment; J. W. Park et al. analyse the resistance of alkali-activated slag concrete to chloride-induced corrosion; E. Gil et al. determine the factors that influence the crystallization of soluble salts in the stone material used in the construction of buildings in Valencia, Spain; and X. Liu et al. address research on dynamic dissolving model and experiment for rock salt under different flow conditions.

S.-M. Chang et al. study the effect of humiditytemperature changing in the below-grade concrete structure with waterproofing materials on the exterior wall; Z. H. Xie et al. describe a numerical study of mesoscopic random aggregate structure containing various rubber contents and aggregate sizes; $\mathrm{M}$. Choi et al. review the technical challenges associated with concrete pumping and the development in concrete pumping; $\mathrm{H}$. Yang et al. study experimentally the 
bond behaviour of corroded reinforced concrete containing recycled aggregates; S.-B. Zhou et al. develop a reformative technique of image segmentation for computer thermography concrete images with the strength grade of C30 and C40; Y. Wang et al. present an experimental study of brittle creep failure, critical behaviour, and the dependence of timeto-failure on the secondary creep rate of concrete under sustained uniaxial compression; X. Wang et al. address numerical simulation to obtain the viscoelastic constitutive relation of high modulus asphalt concrete; Y.-S. Jeong et al. analyse the thermal performance of reinforced concrete floor structure with radiant floor heating system; Y. Guo et al. study the influence of aggregate wettability with different lithology aggregates on concrete drying shrinkage; L. F. Jiménez and E. I. Moreno analyse the durability indicators in high absorption recycled aggregate concrete; G. G. Prabhu et al. study the mechanical and durability properties of concrete made with used foundry sand as fine aggregate; J. Yue presents a micro-macro simulation technique combined with multilevel damage assessment methodology, in order to assess the inherent damage mechanism of reinforced concrete structures; and M. Aswin et al. study the shear failure of reinforced concrete dapped-end beams.

Besides those, there are several interesting topics in the issue. D.-H. Chung et al. improved the structure of highspeed roller door with water film; J.-Y. Lee et al. study the control of geometric pattern using digital algorithm; J. Zhang et al. develop an improved technique for geosyntheticreinforced and pile-supported embankment; $\mathrm{H}$. He et al. simulate aggregate structure and fresh cement paste by a discrete element modelling system; Y. Zhang et al. present an experimental study of stress relaxation behaviours under different temperatures of PTFE coated fabrics; R. Huo et al. develop a simple and innovative sandwich bridge deck with GFRP face sheets and a foam-web core, manufactured by vacuum assisted resin infusion process; Y. Qiang and Y. Chen present another experimental research on the mechanical behaviour of lime-treated soil under different loading rates; X.-F. Jin et al. study the stability of three-dimensional slurry trenches with inclined ground surface; K. Hong et al. investigate experimentally the effectiveness of hybrid FRP-FRCM for shear strengthening; Y. Wang et al. study the performance of calcium silicate board partition fireproof drywall assembly with junction box under fire; J. Zhang et al. validate the applicability of 5 micromechanical models based on the shear modulus of the multiscale asphalt materials; K. Ahn and $\mathrm{H}$. Kang analyse the behaviour of a reinforced retaining wall while changing the reinforcement spacing using LS-DYNA, a general finite-element program; D. Koňáková et al. deal with utilization of raw and treated coir pith as potential component of cementitious composites; J. Huh et al. study the locally corroded stiffener effect on shear buckling behaviours of web panel in the plate girder; Q. Liu and W. Feng study the efficiency and economic impact of energy-saving transformation of residential building in different climatic regions of China; $\mathrm{X}$. Shang et al. investigate the micromechanism underlying nonlinear stress-dependent $\mathrm{K} 0$ of clays at a wide range of pressures; P. Reiterman et al. present an experimental study of the composition of refractory fiber-reinforced aluminous cement based composites and its response to gradual thermal loading; $\mathrm{H}$. Ma et al. study the calibration on MEPDG low temperature cracking model and recommendation on asphalt pavement structures in seasonal frozen region of China; and D. Lee and S. Shin present new engineering practice and idea that material topology optimization results may be utilized to optimally decide the positions of web-openings of structural members in a building structure.

Works related with tensile strength are presented by Y.-J. You et al. who study the tensile strength of GFRP reinforcing bars with hollow section; X. Liu et al. propose the cable tension preslack method construction simulation and engineering application for a prestressed suspended dome; J. Guo et al. analyse the impact vibration experimental research on the prestretched rectangular membrane structure; J. Hou and L. Song investigate numerically stress concentration of tension steel bars with one or two corrosion pits; F. Guo et al. present a lateral buckling analysis of the steel-concrete composite beams in negative moment region; J. Y. Oh et al. study the flexural behaviour of prestressed steel-concrete composite members with discontinuous webs; D. Wu et al. propose a new flexural capacity calculation approach considering joint interface displacements influences and properties improvement by confinement steels; $\mathrm{H}$. He et al. study seismic performances of replaceable steel connection with low yield point metal; $\mathrm{H}$. Ziari et al. describe the effectiveness of using steel slag aggregate in improving the engineering properties, especially fatigue life of asphalt concrete produced with steel slag; and X. Liu et al. present a design and model test of a modular prefabricated steel frame structure with inclined braces.

Studies with nanotubes are presented by Q. Li et al. who review current research activities and key advances on multiwalled carbon nanotubes reinforced cementitious composites; and L. Wang et al. present the preparation and mechanical properties of continuous carbon nanotube networks modified $\mathrm{C}_{f} / \mathrm{SiC}$ composite.

Related to studies in tunnels, J. Lai et al. present a new technology and experimental study on snow-melting heated pavement system in tunnel portal; B. Jin et al. study a construction technique considering the optimal sequence of pilot tunnel excavation in order to ensure the safety of constructing process of long-span shallow-buried tunnel; H. Hou et al. present an experimental and numerical investigation of the structural behaviour of thin-walled concrete-filled steel tube used in cable tunnel; and J. Liu et al. describe a case study to evaluate the influence caused by tunnel construction on groundwater environment.

Another important issue is the ecology of building materials; for example, Y.-W. Choi et al. describe an application of high-fluidity concrete containing high volume fly ash; M. Keppert et al. present a wet-treated municipal solid waste incineration fly ash used as supplementary cementitious material; C. Peng and X. Wu present a method for calculating the carbon emissions generated over a building's life cycle; $\mathrm{B}$. J. Lee et al. address a performance evaluation of semiplastic recycled cold asphalt using noncement binders; M. del Río Merino et al. analyse the potential of a new composite (gypsum and fiber waste) including several mineral wools 
waste into a plaster matrix; and C.-L. Hwang and T.-P. Huynh present the engineering performance and the microstructural characterization of 10 ecofriendly construction bricks that were produced using a binder material made from a mixture of class-F fly ash and residual rice husk ash.

Finally, the application of nanomaterials and nanotechnology for building and construction $[1,2]$ is presented by S. Zhuang et al., who describe an experimental study on the thermal response of PCM energy storage block with hole ventilation.

We hope that readers of this special issue will find not only accurate data and updated reviews on the building technologies and construction materials field area, but also important questions to be resolved. This special issue includes both theoretical and experimental developments, providing a self-contained major reference that is appealing to both the scientists and the engineers. At the same time, these topics will be going to the encounter of a variety of scientific and engineering disciplines, such as chemical, civil, agricultural, and mechanical engineering.

\section{J. M. P. Q. Delgado Robert Cerný \\ A. G. Barbosa de Lima \\ A. S. Guimarães}

\section{References}

[1] P. Ahadi, "Applications of nanomaterials in construction with an approach to energy issue," Advanced Materials Research, vol. 261-263, pp. 509-514, 2011.

[2] A. V. Sá, R. M. S. F. Almeida, H. Sousa, and J. M. P. Q. Delgado, "Numerical analysis of the energy improvement of plastering mortars with phase change materials," Advances in Materials Science and Engineering, vol. 2014, Article ID 582536, 12 pages, 2014. 

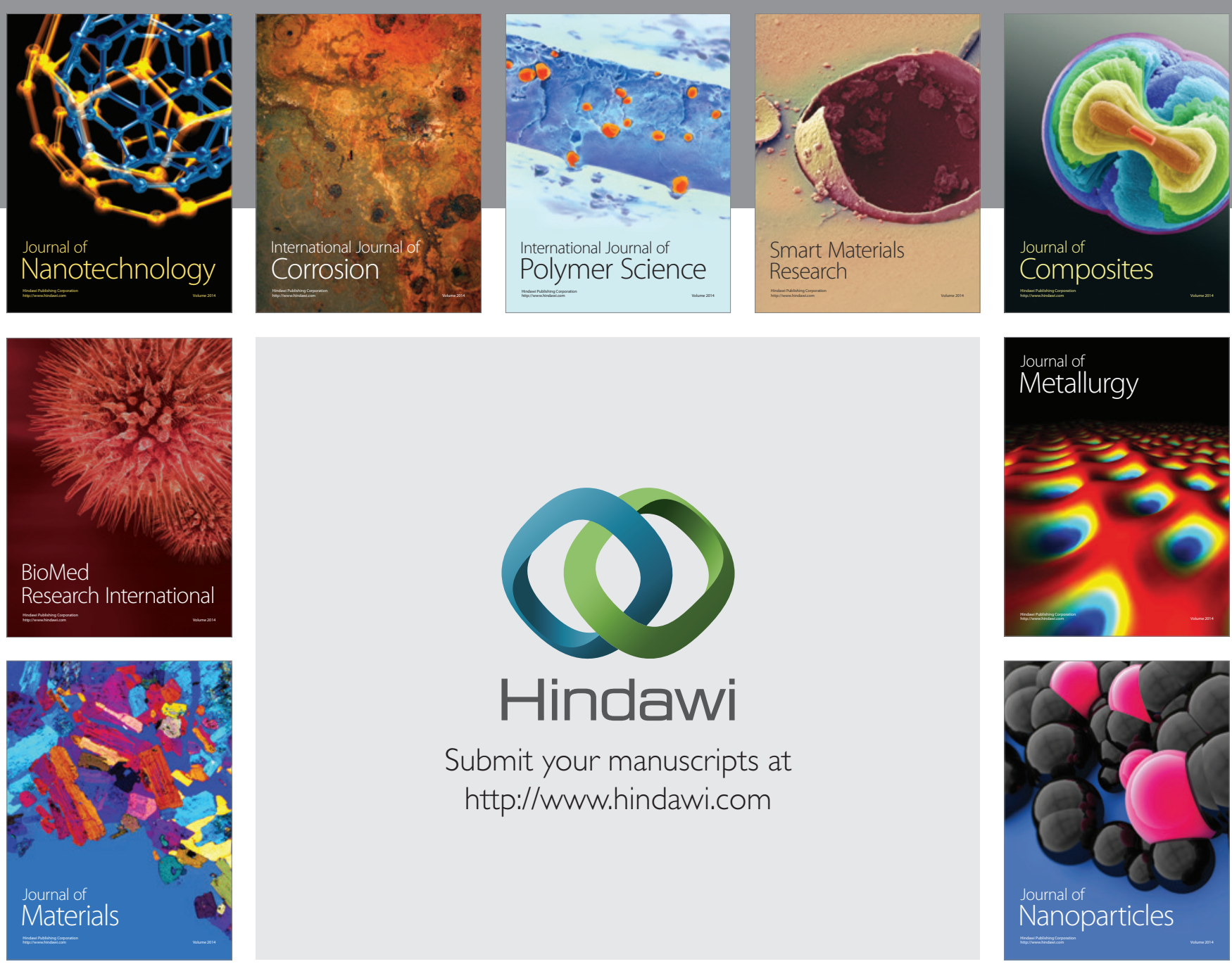

Submit your manuscripts at http://www.hindawi.com
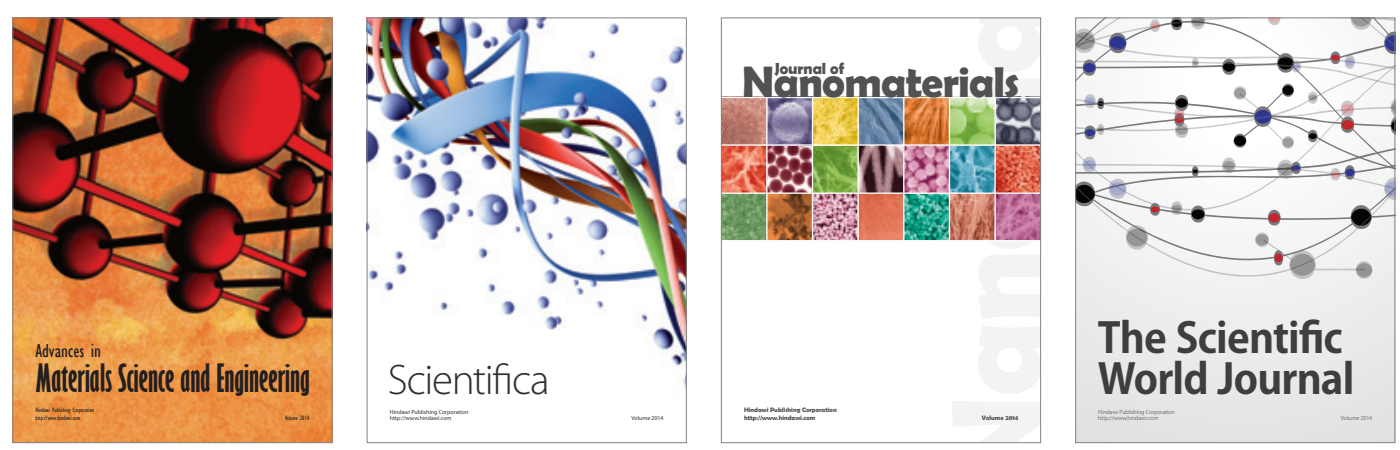

\section{The Scientific World Journal}
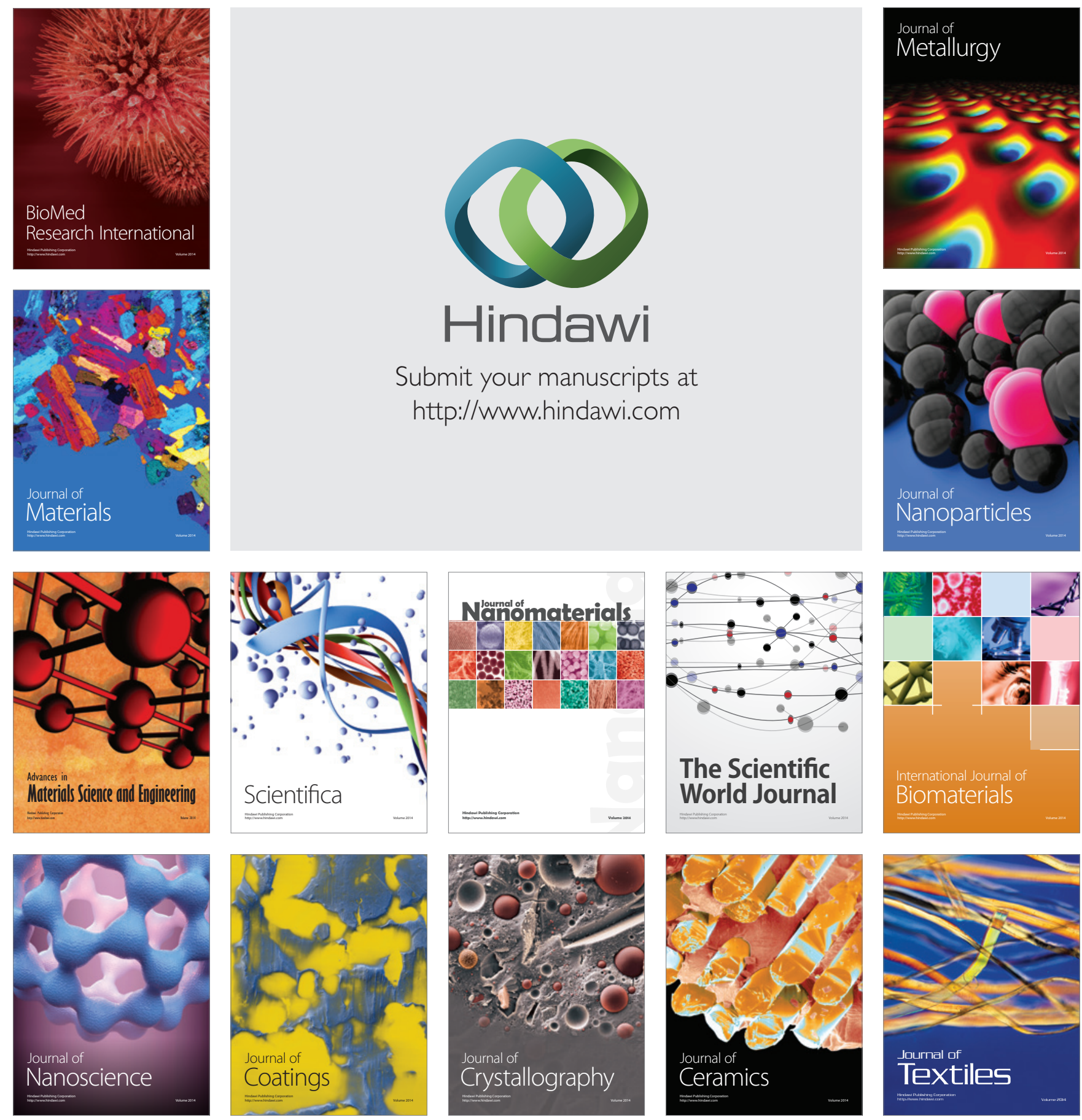